\title{
The Effect of Mechanical Activation \\ on the Physico-Chemical Properties of Carbon Black and Rubber Mixtures Filled with It
}

\author{
Olga A. Knyazheva ${ }^{* a, b}$, Olga N. Baklanova ${ }^{a}$, \\ Alexander V. Lavrenov ${ }^{a}$, Kymbat S. Zhansakovab, \\ Gregory S. Russkikh ${ }^{\mathrm{b}}$ and Vladimir A. Likholobov ${ }^{\mathrm{a}}$ \\ ${ }^{a}$ Institute of Hydrocarbons Processing SB RAS \\ 54 Neftezavodskaya Str., Omsk, 644040, Russia \\ ${ }^{b}$ Omsk State Technical University \\ 11 Mira, Omsk, 644050, Russia
}

Received 26.09.2018, received in revised form 12.11.2018, accepted 02.12.2018

The influence of mechanical activation on porosity, structure (by absorption of dibutyl phthalate $(D B P)$, the size of the agglomerates and the functional surface of the carbon black (CB) N375 was investigated. It was established that in the process of mechanical activation, the number of oxygencontaining groups on the surface CB increases to $0.34 \mathrm{meq} / \mathrm{g}$ and the size of the aggregates decreases from 300 to 3-5 microns. At the same time, the amount of absorption of DBP decreases.

The rubber obtained on the basis of a mixture of SKMS-30 ARK rubber and mechanically activated $C B$ is characterized by increased values of relative elongation under tension and a lower modulus of elasticity.

Keywords: caoutchouck, carbon black, mechanical activation, rubber, physico-mechanical properties.

Citation: Knyazheva O.A., Baklanova O.N., Lavrenov A.V., Zhansakova K.S., Russkikh G.S., Likholobov V.A. The effect of mechanical activation on the physico-chemical properties of carbon black and rubber mixtures filled with it, J. Sib. Fed. Univ. Chem., 2018, 11(4), 552-563. DOI: 10.17516/1998-2836-0099.

(C) Siberian Federal University. All rights reserved

* Corresponding author E-mail address: knyazheva@ihcp.ru 


\title{
Влияние механической активации \\ на физико-химические свойства технического углерода \\ и наполненных им резиновых смесей
}

\author{
О.А. Княжева ${ }^{\text {a, }}$, О.Н. Бакланова ${ }^{a}$, А.В. Лавренов ${ }^{a}$, \\ К.С. Жансакова ${ }^{\tilde{\sigma}}$, Г.С. Русских ${ }^{\mathbf{w}}$, В.А. Лихолобов ${ }^{a}$ \\ ${ }^{a}$ Институт проблем переработки углеводородов СО РАН \\ Россия, 644040, Омск, ул. Нефтезаводская, 54 \\ ${ }^{6}$ Омский государственный технический университет \\ Россия, 644050, Омск, пр. Мира, 11
}

Исследовано влияние механической активации на пористость, структурность по абсорбиии дибутилфталата (ДБФ), размеры агломератов и функциональный покров поверхности технического углерода (TУ) марки N375. Установлено, что в процессе механической активации возрастает количество кислородсодержащих групп на поверхности ТУ от 0,12 до 0,34 мэкв/ح и снижается размер агрегатов от 300 до 3-5 мкм. Одновременно снижается величина абсорбиии ДБФ.

Резина, получаемая на основе смеси каучука марки СКМС-30 АРК и механоактивированного ТУ, отличается повыменными значениями относительного удлинения при растяжении и более низким модулем упругости.

Ключевые слова: каучук, технический углерод, механическая активачия, резина, физикомеханические свойства.

\section{Введение}

Технический углерод (ТУ, сажа) относится к классу промышленных углеродных продуктов, где углерод находится в форме, которая не встречается в природных материалах. Это полидисперсный порошкообразный материал черного цвета, образующийся в газовой фазе при термическом или термоокислительном разложении углеродсодержащих веществ, преимущественно углеводородов [1].

ТУ относят к переходным (смешанным) формам углерода [2]. ТУ характеризуется наличием микрокристаллитов с дефектной графитоподобной структурой, находящихся в окружении взаимосвязанных аморфных участков. Характерной особенностью атомного строения ТУ является тот факт, что в графитоподобной составляющей атомы углерода находятся в состоянии $\mathrm{sp}^{2}$-гибридизации, а в аморфной части имеются атомы $\mathrm{sp}^{3}-, \mathrm{sp}^{2}-$, $\mathrm{sp}$ гибридизации [3].

Морфологической особенностью ТУ (рис. 1) является образование из первичных частиц (глобул) углерода цепочек, которые соединяются и разветвляются в пространстве, формируя вторичные частицы (агрегаты) разной формы с повышенной прочностью за счет поверхностных химических связей C-C- или C-O-, а также их прямого срастания $[3,4]$. Агрегаты, в свою 


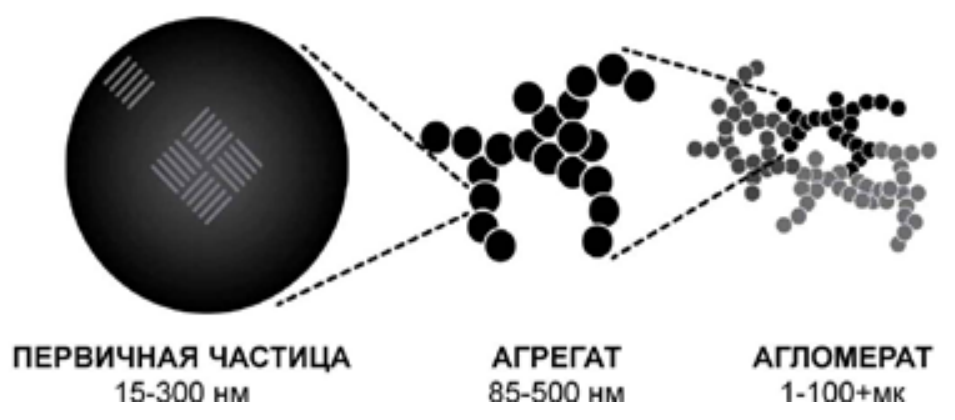

Рис. 1. Строение технического углерода

Fig. 1. The structure of carbon black

очередь, за счет слабых ван-дер-ваальсовых сил взаимодействия могут группироваться в агломераты, образуя рыхлый пространственный каркас [2]. В зависимости от условий получения и дополнительной обработки образцов ТУ эффективный размер глобул, агрегатов, агломератов в техническом углероде, а значит, их удельная поверхность, могут варьироваться в широких пределах.

Основной областью применения ТУ (80 \% от выпускаемого объема) является использование его в качестве усиливающего компонента в производстве резин на основе натурального и синтетических каучуков. Наполнение им каучуков существенно повышает прочностные характеристики резин, такие как твердость, износостойкость, а также снижает разбухание полуфабрикатов при экструзии и усадку готовых резиновых изделий $[5,6]$. Однако, как продемонстрированно в работах [7-11], отсутствие функциональных групп на поверхности ТУ (карбоксильных, лактонных и др.) ухудшает химическое и физическое взаимодействие между частицами ТУ и молекулами каучука. В работе [12] показано, что в процессе озонирования ТУ марки N330 (производитель Gabot) содержание кислорода увеличивается с 0.9 до 12 масс. \%. Окисленный ТУ был использован в качестве усиливающего компонента для бутадиеннитрильного каучука (БНК). Установлено, что предел прочности при растяжении для резин, полученных на основе полярного БНК, увеличивается с 16.4 (неокисленный ТУ) до 22.2 (окисленный ТУ) МПа. Авторы данный эффект связывают с тем, что увеличение кислородсодержащих групп на углеродной поверхности ТУ, образовавшееся в процессе окисления, приводит к уменьшению плотности поперечного сшивания каучука, что в свою очередь приводит к уменьшению твердости резины. В работе [13] в качестве усиливающего компонента для эпоксидированного натурального каучука (НК) был использован окисленный TУ Printex-550 (Degussa AG). Установлено, что кислородсодержащие группы окисленного ТУ взаимодействуют с молекулами эпоксидированного НК, образуя связи эфирного типа, а также водородные и ван-дерваальсовые связи. Это приводит к снижению модуля упругости резиновых смесей.

В работах [14] для окисления углеродной поверхности ТУ N324 (Tianjin Haitun Carbon Black Industry) было использовано излучение высокоэнергетическим лучом при дозах от 100 до 700 кГр. Показано, что окисление в данных условиях приводит к увеличению количества лактонных и хинонных кислородсодержащих групп на поверхности ТУ, а также к снижению размера частиц агломератов ТУ с 319 до 220.8 нм. Обнаружено, что резины на основе НК при

$$
-554-
$$


введении окисленного ТУ обладают более высокими значениями предела прочности при растяжении 20.4 МПа.

В последние годы интенсивно развиваются методы модифицирования углеродных материалов при механическом воздействии [15-18]. Метод механической активации (МА) рассматривается как способ повышения гидрофильности углеродной поверхности таких углеродных материалов, как графит и ТУ. В работе [17] показано, что МА синтетического графита на воздухе в высокоэнергетической планетарной мельнице АГО-2 в течение 60 мин при ускорении $100 \mathrm{~g}$ способствует снижению размера агрегатов с 28,5 до 6,9 мкм через 30 мин МА. При этом обнаружено, что при проведении МА на поверхности графита формируются гидроксильные, фенольные, лактонные и карбонильные группы в количестве до 0,8 мэкв/г. Авторы работы [19] провели механохимический синтез интеркалированных соединений графита и фуллерита на воздухе при использовании роликокольцевой вибромельницы VM-4. Установлено, что в результате МА происходит интеркаляция кислорода между поверхностными графеновыми слоями. При накоплении достаточного количества кислорода происходит его химическое взаимодействие с поверхностными атомами углерода, приводящее к образованию поверхностных групп различного типа.

В рамках данной работы изучено влияние механической активации технического углерода на его физико-химические показатели, такие как удельная поверхность, размер частиц, содержание примесей, показатель структурности и наличие кислородсодержащих групп на поверхности, а также на изменение физико-механических свойств полученных с его применением резин.

\section{Экспериментальная часть}

В качестве объекта исследования использовали печной ТУ марки $\mathrm{N} 375$, произведенный на предприятии ОАО «Омсктехуглерод». В табл. 1 приведены физико-химические показатели ТУ марки N375.

Механическую активацию ТУ проводили на воздухе в водоохлаждаемой планетарной мельнице АГО-2 при ускорении мелющих тел 1000 м/с² в течение 5 мин. В качестве мелющих тел использовали стальные шары марки - ШХ-15 диаметром 2 и 8 мм. Соотношение масс шаров к массе ТУ составляло 1:35.

Таблица 1. Физико-химические показатели технического углерода N375

Table 1. Physico-chemical characteristics of carbon black N375

\begin{tabular}{|c|c|}
\hline Показатель & Значение \\
\hline Удельная геометрическая поверхность, м²/г $^{2}$ & 96 \\
\hline Абсорбция дибутилфталата (структурность), см³/100 г & 87 \\
\hline pH водной суспензии & $6-8$ \\
\hline Содержание золы, \% мас. & 0,22 \\
\hline 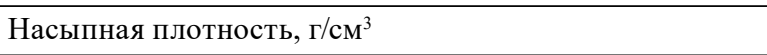 & 0,28 \\
\hline Количество кислородсодержащих групп, мэкв/г & 0,12 \\
\hline
\end{tabular}


Характеристики удельной поверхности и пористой структуры исследуемых образцов были получены из анализа изотерм адсорбции-десорбции $\mathrm{N}_{2}$, измеренных при минус $195,97^{\circ} \mathrm{C}$ (77,4 K), на объемной вакуумной статической установке ASAP-2020, «Micrometrics». Перед проведением адсорбционных измерений образец помещали в дегазационный порт прибора и тренировали в вакууме при $250{ }^{\circ} \mathrm{C}$ в течение 5 ч.

Определение содержания кислородсодержащих функциональных групп на поверхности ТУ проводили методом кислотно-основного титрования, описанного подробно в [20].

Для оценки типов кислородсодержащих групп, находящихся на поверхности частиц ТУ, образец исходного ТУ и механоактивированные образцы были исследованы методом ИКспектроскопии. Для проведения ИК-анализа образцы ТУ напыляли на пластинку из $\mathrm{BaF}_{2}$. ИКспектры регистрировали на спектрометре IRPrestige-21, «Shimadzu» с разрешением $4 \mathrm{~cm}^{-1}$ и числом накопления спектров 50.

Определение абсорбции дибутилфталата (ДБФ) образцов ТУ проводили по ASTMD 2414-04.

Содержание металлов в исходном и механоактивированных образцах ТУ определяли методом атомно-эмиссионной спектрометрии с индуктивно связанной плазмой (АЭС-ИСП) на приборе VARIAN 710-ES, «AgilentTechnologies».

Для исследования влияния механической активации ТУ на изменение его эксплуатационных показателей были приготовлены резиновые смеси. В качестве полимерной матрицы при приготовлении резин был использован эмульсионный бутадиен-стирольный каучук марки СКМС-30 АРК производства компании «Омский каучук». Рецептура резиновой смеси, режимы смешения и вулканизации были выбраны в соответствии с ASTMD 3185-06. В качестве углеродных наполнителей в резиновые смеси вводили исходный ТУ марок N375 и образцы ТУ марки N375 после МА. Состав резиновых смесей приведен в табл. 2.

Рецептура резиновых смесей на основе бутадиен-стирольного каучука СКМС-30 АРК и ТУ марки N375 и механоактивированных образцов ТУ во всех экспериментах оставалась постоянной.

Оценку упруго-прочностных свойств резиновых смесей при растяжении проводили по ASTM D 412.

Механические свойства резин - модуль упругости Е' и тангенс угла механических потерь $\operatorname{tg} \delta$ - исследовали при осцилляции 1 Гц в режиме «деформация-растяжение» с по-

Таблица 2. Рецептура резиновых смесей

Table 2. Composition of the rubber mixture

\begin{tabular}{|c|c|}
\hline Наименование компонента & $\begin{array}{c}\text { Массовая доля } \\
\text { компонента в смеси, мас. ч. }\end{array}$ \\
\hline Каучук СКМС-30 АРК & 100,00 \\
\hline Технический углерод & 50,00 \\
\hline Техническая сера & 1,75 \\
\hline Стеариновая кислота & 1,00 \\
\hline Оксид цинка & 3,00 \\
\hline Сульфенамид (ТВBS) & 1,00 \\
\hline
\end{tabular}


мощью динамического механического анализатора DMA 242D фирмы «NETZSCH» (Германия).

\section{Результаты и обсуждение}

Влияние механической активации на изменение физико-химических свойств технического углерода

В табл. 3 приведены показатели пористой структуры исходного ТУN375 и механоактивированных образцов.

Как можно видеть, в процессе МА технического углерода при увеличении диаметра мелющих тел с 2 до 8 мм при одинаковом ускорении мелющих тел наблюдается увеличение удельной поверхности с 87 до 124 и 259 м²/г соответственно. При этом суммарный объем пор $\mathrm{V}_{\Sigma}$ и объем мезопор $\mathrm{V}_{\text {meso }}$ снижается за счет уменьшения доли крупных пор и увеличения доли более тонких мезопор, что сопровождается снижением среднего размера пор.

В табл. 4 приведены показатели абсорбции ДБФ, содержание золы и количество кислородсодержащих групп для исходного N375 и механоактивированных образцов.

Как видно из данных табл. 4, МА технического углерода приводит к снижению показателя абсорбции ДБФ по сравнению с исходным ТУ с 98 до 50 мл/100г и увеличению содержания минеральных примесей в составе ТУ до 0,51-0,93 \%. Положительным результатом МА ТУ N375 при выбранных параметрах можно считать возрастание количества кислородсодержащих групп на углеродной поверхности до 0,34 мэкв/г.

Таблица 3. Изменение пористой структуры технического углерода в процессе механической активации Table 3. The changing in the porous structure of carbon black in the process of mechanical activation

\begin{tabular}{|c|c|c|c|c|c|}
\hline $\begin{array}{c}\text { Диаметр } \\
\text { мелющих тел, } \\
\text { мм }\end{array}$ & $\begin{array}{c}\text { Удельная } \\
\text { площадь } \\
\text { поверхности, } \\
\mathrm{S}_{\mathrm{BET}, \mathrm{M}^{2} / \Gamma}\end{array}$ & $\begin{array}{c}\text { Суммарный } \\
\text { объем пор, } \\
\mathrm{V}_{\Sigma}, \mathrm{cm}^{3} / \Gamma\end{array}$ & $\begin{array}{c}\text { Объем мезопор, } \\
\mathrm{V}_{\text {meso }}, \mathrm{cm}^{3} / \Gamma\end{array}$ & $\begin{array}{c}\text { Объем } \\
\text { микропор, } \\
\mathrm{V}_{\text {mi, }}, \mathrm{cm}^{3} / \Gamma\end{array}$ & $\begin{array}{c}\text { Средний } \\
\text { размер пор, } \\
\mathrm{D}_{\text {В.н }}, \text { нм }\end{array}$ \\
\hline- & 87 & 0,894 & 0,892 & 0,002 & 44 \\
\hline 2 & 124 & 0,653 & 0,640 & 0,013 & 28 \\
\hline 8 & 259 & 0,412 & 0,359 & 0,053 & 15 \\
\hline
\end{tabular}

Таблица 4. Изменение физико-химических показателей технического углерода в процессе механической активации

Table 4 . The changing the physic-chemical properties of carbon black in the process of mechanical activation

\begin{tabular}{|c|c|c|c|}
\hline $\begin{array}{c}\text { Диаметр } \\
\text { мелющих тел, мм }\end{array}$ & $\begin{array}{c}\text { Абсорбция ДБФ, } \\
\text { мл/100 г }\end{array}$ & Содержание золы, \% & $\begin{array}{c}\text { Количество } \\
\text { кислородсодержащих } \\
\text { групп, мэкв/г }\end{array}$ \\
\hline- & 95 & 0,22 & 0,12 \\
\hline 2 & 52 & 0,51 & 0,34 \\
\hline 8 & 51 & 0,93 & 0,34 \\
\hline
\end{tabular}


Соответственно, при увеличении количества кислородсодержащих групп в механоактивированных образцах ТУ фиксируется снижение рН водной суспензии до 3,5 - 3,8.

Для исходного и механоактивированного образцов ТУ были получены ИК-спектры, которые приведены на рис. 2.

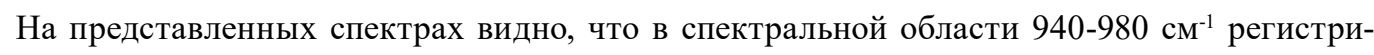
руется п.П., вероятно, относящаяся к внеплоскостным деформационным колебаниям связей $\mathrm{C}-\mathrm{H}$ в структурном фрагменте $\mathrm{CHR}_{1}=\mathrm{CHR}_{2}-$ в транс-конфигурации. В спектральной области

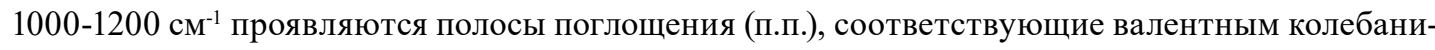
ям связей С-О в фенольных и спиртовых структурах. В спектральной области 1200-1300 см-1 исследуемых образцов регистрируются п.п., отвечающие валентным колебаниям связей $\mathrm{C}-\mathrm{O}$ в эфирных и лактонных структурах. Наблюдаемые п.п. в спектральной области 1540-1590 $\mathrm{cm}^{-1}$ соответствуют валентным колебаниям связей $\mathrm{C}=\mathrm{C}$ в ароматическом кольце сопряженных систем. Для образца МА-8-100 в спектральной области 1700-1750 регистрируется п.п., которая относится к валентным колебаниям связей $\mathrm{C}=\mathrm{O}$ кетонной и карбонильной групп. Полученные результаты свидетельствуют о том, что механическая активация технического углерода при ускорении мелющих тел $100 \mathrm{~g}$ и использовании мелющих тел диаметром 8 мм приводит к образованию сопряженных связей $\mathrm{C}=\mathrm{O}$ типа $\mathrm{O}=\mathrm{C}-\mathrm{C}=\mathrm{C}$.

На рис $3 a$,б представлены гистограммы распределения частиц по размерам для исходного ТУ N375, которые были диспергированы в воде (рис. $3 a$ ) и в водных растворах анионного поверхностно-активного вещества (ПАВ) додецилсульфатнитрая ДСН (рис. 3б).

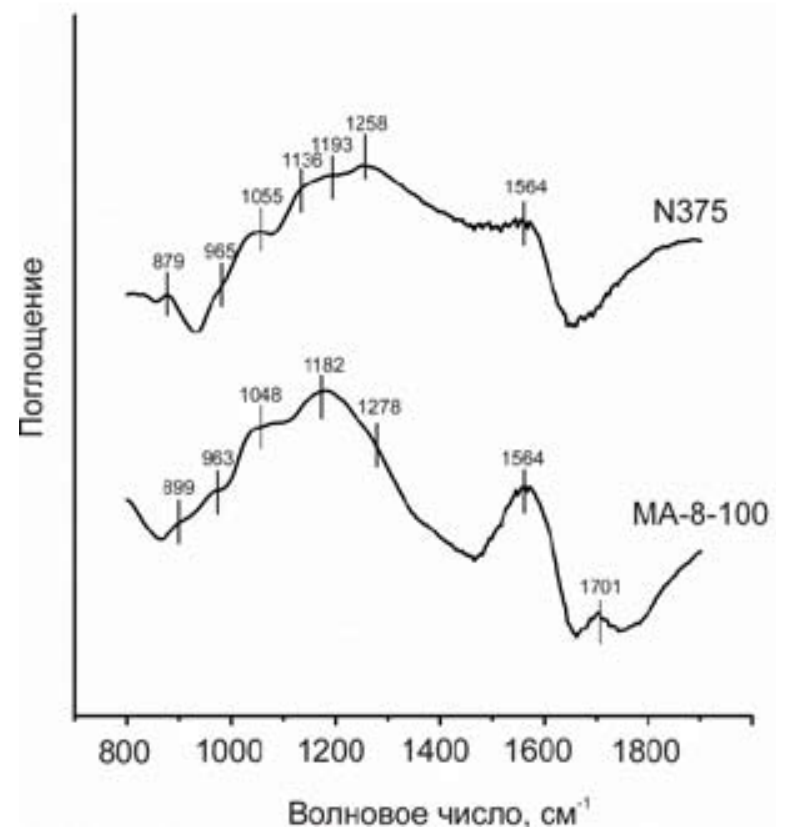

Рис. 2. ИК-спектры технического углерода N375 и образца МА-8-100, механоактивированного мелющими телами диаметром 8 мм при ускорении мелющих тел $100 \mathrm{~g}$

Fig. 2. IR-spectra of carbon black N375 and mechanically activated sample by milling bodies with a diameter of $8 \mathrm{~mm}$ at a $100 \mathrm{~g}$ acceleration of milling bodies 

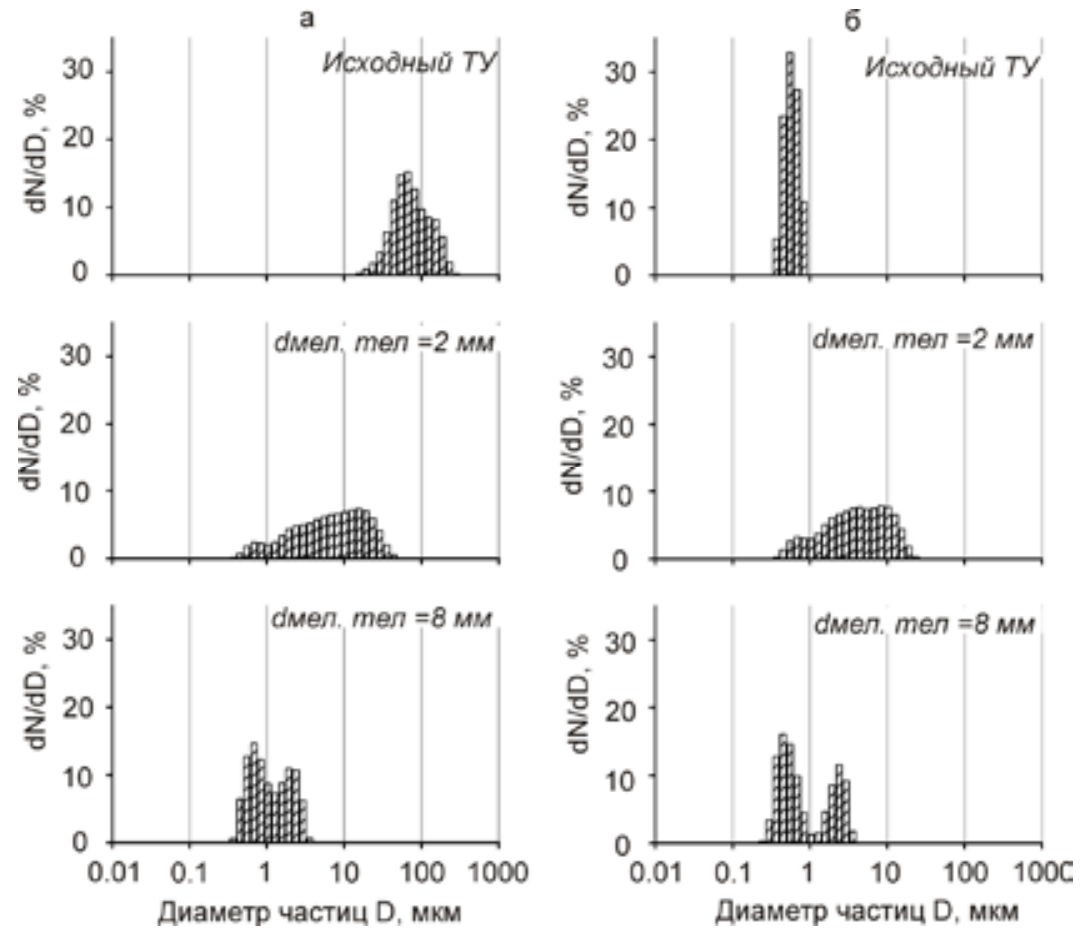

Рис. 3. Гистограммы распределения частиц по размерам исходного ТУ N375 и механоактивированных образцов ТУ в воде (а) и в водных растворах ДСН (б). Механоактивация ТУ проводилась мелющими телами $\mathrm{d}=2 \mathrm{mм}-\mathrm{d}=8$ мм - указано на рисунке

Fig. 3. Histograms of the distribution of particle sizes of the carbon black N375 and mechanically activated samples of CB in water (a) and in aqueous solutions of SDS (б). Mechanical activation of was carried out with milling bodies of $\mathrm{d}=2 \mathrm{~mm}-\mathrm{d}=8 \mathrm{~mm}$ - indicated in the figure

Изображены гистограммы распределения частиц по размерам для образцов, механоактивированных мелющими телами $\mathrm{d}=2$ мм (рис. $2 a, \sigma)$ и $\mathrm{d}=8$ мм (рис. $3 a, \sigma)$.

Как видно на рис. $3 a$, исходный ТУ N375 диспергируется в воде до агломератов с размерами 20 - 300 мкм. При диспергировании ТУ N375 в водном растворе анионного ПАВ - ДСН размер сажевых агрегатов ТУ N375 снижается и составляет 0,3 - 1,0 мкм (рис. 36).

Гистограммы распределения частиц по размерам для механоактивированных образцов ТУ свидетельствуют о следующем. При диспергировании в воде образца ТУ, механоактивированного мелющими телами диаметром 2 мм (рис. $3 a$ ), размер частиц значительно снижается по сравнению с исходным ТУ и составляет 0,6 - 60 мкм. Введение ПАВ в состав водной среды для данного образца практически не оказывает влияния на размер частиц (рис. 3б), размеры углеродных частиц при диспергировании в водном растворе ПАВ находятся в тех же пределах, что и при диспергировании в воде.

Размер частиц ТУ после механической активации мелющими телами диаметром 8 мм в воде составляет 0,5-5,0 мкм (рис. 3a). Введение ПАВ в состав дисперсионной среды, как и для ТУ, механоактивированных мелющими телами с диаметром 2 мм, не приводит к изменению вида гистограмм распределения частиц по размерам (рис. 3б). Таким образом, полученные результаты свидетельствуют о возможности получения водных суспензий технического 
углерода с размерами частиц в интервале 0,5 - 5,0 мкм без введения в состав водной среды поверхностно-активных веществ.

\section{Физико-химические свойства резин}

В соответствии с ASTMD 3185-06 были приготовлены три резиновых смеси. В качестве активного наполнителя в резиновые смеси были введены технический углерод N375 и образцы технического углерода после механической активции в течение 5 мин мелющими телами диаметром 2 и 8 мм при ускорении мелющих тел $100 \mathrm{~g}$.

Оценку упруго-прочностных вулканизованных резин при растяжении проводили по ГОСТ 270-75. В табл. 5 представлены основные физико-механические характеристики вулканизованных резин, полученных на основе каучука СКМС-30 АРК и углеродных наполнителей.

Как видно из данных табл. 5, модуль упругости для резин, наполненных механоактивированным техническим углеродом, имеет меньшие значения по сравнению с резиной, наполненной промышленным ТУ N375.

Можно предположить, что снижение модуля упругости в этом случае обусловлено меньшими размерами частиц механоактивированного ТУ (см. рис. 3). Это приводит к формированию резиновой смеси с более подвижной структурой, с меньшими временами релаксации и, соответственно, меньшими значениями модуля упругости.

Относительное удлинение при разрыве для резины с механоактивированным ТУ имеет более высокие значения, что обусловлено, на наш взгляд, двумя факторами:

- малыми размерами частиц углеродного механоактивированного наполнителя, что облегчает перемещение элементов ламелярной структуры каучука по поверхности углеродных частиц без разрушения;

- более высоким содержанием функциональных групп на углеродной поверхности механоактивированных ТУ, более чем в 2,5 раза превышающих количество групп на поверхности исходного образца ТУ. Отмеченное увеличение количества функциональных групп на поверхности ТУ приводит к повышению числа контактов макромолекул каучука с функционализированной поверхностью технического углерода, что и обуславливает стабильное течение полимерного композита, сопровождающееся возрастанием относительного удлинения при растяжении.

Таблица 5. Физико-механические свойства вулканизованных резин

Table 5. Physico-mechanical properties of vulcanized rubber composites

\begin{tabular}{|l|c|c|c|}
\hline \multirow{2}{*}{ Наименование показателя } & \multicolumn{3}{|c|}{ Углеродный наполнитель } \\
\cline { 2 - 4 } & $\mathrm{N} 375$ & $\mathrm{~N} 375-\mathrm{MA}-2$ & $\mathrm{~N} 375-\mathrm{MA}-8$ \\
\hline Модуль упругости, МПа & 6,80 & 3,78 & 4,40 \\
\hline Условное напряжение при 100 \% удлинении, МПа & 1,50 & 1,44 & 1,56 \\
\hline Условное напряжение при 200 \% удлинении, МПа & 2,46 & 2,26 & 2,47 \\
\hline Условное напряжение при 300 \% удлинении, МПа & 3,69 & 3,30 & 3,56 \\
\hline Условная прочность при растяжении, МПа & 18,30 & 22,00 & 17,60 \\
\hline Относительное удлинение при разрыве, \% & 1007,00 & 1177,30 & 1053,80 \\
\hline
\end{tabular}


Особенно заметны изменения в прочностных свойствах резин при введении ТУ после МА мелющими телами с диаметром 2 мм. Для резины с данным ТУ характерным является малое значение модуля упругости - 3,78 МПа, малые значения условных напряжений при 100, 200 и 300 \% удлинения. Однако результирующее значение условной прочности при растяжении превышает условную прочность резины с промышленным ТУ марки N375 и составляет 22,00 МПа. Относительное удлинение при разрыве для образца резины с механоактивированным ТУ равно 1177,30 \%, что превышает уровень данного показателя даже для резины с промышленным ТУ. Обобщая вышеизложенное, можно сказать, что введение механоактивированного печного ТУ позволяет получать более «мягкую” резину, обладающую малыми значениями модуля упругости и высокими значениями относительного удлинения при разрыве, превышающими уровень данных показателей для резин с наполнителем - канальным ТУ.

\section{Заключение}

Изучено влияние параметров МА (диаметра мелющих тел, ускорения мелющих тел и времени) на изменение размеров частиц ТУ, текстурных характеристик и функционального покрова углеродной поверхности. Установлено, что размер агрегатов ТУ в процессе МА снижается практически на два порядка. При всех режимах МА обнаружено снижение показателя абсорбции ДБФ, обусловленное разрушением крупных агломератов ТУ при механическом воздействии, и повышение зольности за счет частичного разрушения мелющих тел в процессе МА. Установлено, что при ускорении мелющих тел $100 \mathrm{~g}$ практически в три раза возрастает количество кислородсодержащих групп на поверхности ТУ и, соответственно, снижается рН водной суспензии ТУ до 3,5-3,8.

На основе каучука марки СКМС-30 АРК и механоактивированного ТУ приготовлены и вулканизованы резиновые смеси, проведена оценка их физико-механических свойств. Показано, что введение в состав резины механоактивированного печного ТУ приводит к получению более «мягкой» резины, обладающей пониженным значением модуля упругости 3,78 МПа и более высокой величиной относительного удлинения при растяжении $1177,30 \%$, по сравнению с аналогичными показателями для резиновых смесей с промышленным техническим углеродом марки N375.

Работа выполнена в рамках государственного задания ИППУ СО РАН в соответствии с Программой фундаментальных научных исследований государственных академий наук на 2013-2020 годы по направлению V.49, проект № V.49.1.6 (номер госрегистрации в системе ЕГИСУ НИОКТР АААA-А17-117021450100-2).

Физико-химические исследования исходныхматериалов и опытных образцов проводились с использованием научного оборудования Омского регионального Центра коллективного пользования СО РАН.

\section{Список литературы}

1. Большой справочник резинщика. Ч.1. Каучуки и ингредиенты. Под ред. С.В. Резниченко, Ю.М. Морозова М.: ООО Изд. Центр «Техинформ» МАИ, 2012. 744 с. [Large Handbook of 
Rubber Specialist. Part 1: Rubbers and Ingredients / Ed. S.V. Reznichenko, Yu.L. Morozov, Tekhinform Ltd., Moscow, 2012, 744 p. (In Russ.)]

2. Long Ch.M.,NascarellaM.A., Valberg P.A. Carbon black vs. black carbon and other airborne materials containing elemental carbon: Physical and chemical distinctions. Environmental Pollution 2013. Vol. 181, P. 271-286.

3. Donnet J.B., Bansal R.C., Wang M.J. Carbon Black Science and Technology. Dekker, New York. 1993. $461 \mathrm{p}$.

4. Lockwood F.C., Niekerk J.E. Parametric study of a carbon black oil furnace. Combustion Flame. 1995. Vol.103, P. 76-90.

5. Iftekharul Islam, Shahin Sultana, Swapan Kumer Ray, Husna Parvin Nur, Md. Tofazzal Hossain, Walliullah Md. Ajmotgir. Electrical and tensile properties of carbon black reinforced polyvinyl chloride conductive composites. Journal of Carbon Research 2018. Vol. 4(15), P. 2-12.

6. Mostafa A., Abouel-Kasem A., Bayoumi M.R., El-Sebaie M.G. Rubber-filler interactions and its effect in rheological and mechanical properties of filled compounds. Journal of Testing and Evaluation 2010. Vol. 38 (3), P. 347-359.

7. Jovanović V., Samaržija-Jovanović S., Budinski-Simendić J., Marković G., MarinovićCincović M. Composites based on carbon black reinforced NBR/EPDM rubber blends. Compos Part B: Eng 2013. Vol. 45, P. 333-340.

8. Araby S., Meng Q., Zhang L., Zaman I., Majewski P., Ma J. Elastomeric composites based on carbon nanomaterials. Nanotechnology 2015. Vol. 26, P. 112001.

9. Griffini G., Suriano R., Turri S. Correlating mechanical and electrical properties of filler-loaded polyurethane fluoroelastomers: the influence of carbon black. PolymEngSci. 2012. Vol. 52, P. 25432551.

10. Korai Y., Wang Y.G., Yoon S.H., Ishida S., Mochida I., Nakagawa Y., Matsumura Y. Effects of carbon black addition on preparation of meso-carbon microbeads. Carbon 1997. Vol. 35, P. 875-884.

11. Kanno K., Fernandez J.J., Fortin F., Korai Y., Mochida I. Modifications to carbonization of mesophase pitch by addition of carbon blacks. Carbon 1997. Vol. 35, P. 1627-1637.

12. Sutherland I., Sheng E., Bradley R.H., Freakley P.K. Effects of ozone oxidation on carbon black surfaces. Journal of materials science 1996. Vol. 31, P. 5651-5655.

13. Manna A.K., De P.P., Tripathy D.K., DE S.K. Hysteresis and strain-dependent dynamic mechanical properties of epoxidized natural rubber filled with surface-oxidized carbon black. Journal of Applied Polymer Science 1998. Vol. 70, P. 723-730.

14. Yongpeng Wu, Shipeng Wen, Jing ShenJian Jiang, Shui Hub, Liqun Zhang, Li Liu. Improved dynamic properties of natural rubber filled with irradiation- modified carbon black. Radiation Physics and Chemistry 2015. Vol. 111, P. 91-97.

15. Gorbunova O.V., Vasilevich A.V., Baklanova O.N., Arbuzov A.B., Poserkova Y.S., Likholobov V.A. The influence of the mechanical activation on the graphite electric conductivity. Procedia Engineering 2015. Vol. 113, P. 484-489.

16. Nikonova R.M., Larionova N.S., Ladyanov V.I., Aksenova V.V., Rud A.D., Kirian I.M. Changes of the structure of fullerite and graphite during their mechanical activation. J. Alloys and Compounds 2016. Vol. 682, P. 61-69. 
17. Baklanova O.N., Drozdov V.A., Lavrenov A.V., Vasilevich A.V., Muromtsev I.V., Trenikhin M.V., Arbuzov A.B., Likholobov V.A., Gorbunova O.V. Mechanical activation of graphite in air: A way to advanced carbon nanomaterials. J. Alloys and Compounds 2015. Vol. 646, P. 145-154.

18. Аввакумов Е.Г. Механические методы активации химических процессов. Новосибирск: Наука, 1986. 305 с. [Avvakumov E.G. Mechanical methods of activation of chemical processes. Novosibirsk: Science, 1986. 305 c. (In Russ.)].

19. Barton S.S., Evans M.J.R., Halliop E., MacDonal J.A.F. Acidic and basic sites on the surface of porous carbon. Carbon 1997. Vol. 35, P. 1361-1366.

20. Boehm H.P. Some aspects of the surface chemistry of carbon blacks and other carbons. Carbon. 1994. Vol. 32. P. $759-769$. 